\title{
Genetic Diversity in Tomato (Solanum lycopersicum) and Its Wild Relatives
}

\author{
Guillaume Bauchet and Mathilde Causse \\ Institut National de la Recherche Agronomique (INRA), \\ Unité de Génétique et Amélioration des Fruits et Légumes (GAFL),
}

France

\section{Introduction}

Tomato, ranking $1^{\text {st }}$ in the world for vegetables, accounts for $14 \%$ of world vegetable production (over 100 million metric tons/year \$ 1.6 billion market; (Food and Agriculture Organisation [FAO] 2010). Tomato is a rich source of micronutrients for human diet. It is also an acknowledged model species for research on fruit development and metabolite accumulation. The major goals of tomato breeders (higher productivity, better tolerance to biotic and abiotic stresses and increased sensory and health value of the fruit) require a good comprehension and management of tomato genetic resources diversity.

Due to its Latin American origin and related domestication history, cultivated tomato has faced several bottlenecks over ages. This led to a drastic reduction of its genetic diversity. Explorations of tomato center of origin permitted major advances in the characterization of its diversity. In parallel, ex situ plant conservation initiatives bloomed, ensuring the collection and conservation of landraces and wild species through development of seed banks. Thus, unraveling the genetic potential of tomato's wild relatives for breeding purpose emerged. In parallel, the ecological and taxonomic diversity of tomato turned it into a model species for evolutionary studies. Since the mid-20th century, new methods such as controlled hybridization allowed crossing between wild and cultivated tomato. Modern genetics and breeding methods contributed to understand the genetic control of agronomical traits but also accentuated the progress. If successful, the accuracy to introgress agronomic traits of interest from wild relatives into cultivated tomato was not always straightforward. This was notably due to inherent linkage between "favorable" and "unfavorable" effects of introgressed fragments.

The advent of molecular biology in the 80's raised great hopes in terms of characterization of the genetic diversity present in both wild and cultivated compartments. Also, great expectations emerged since the development of molecular techniques to "pinpoint" genomic regions involved in targeted traits. Dissection of the genetic control of complex traits, using ad hoc techniques from quantitative genetics, was possible, leading to the identification of key alleles involved in diverse agronomic traits, originating from several wild relatives.

Today the tomato genome is fully sequenced. A new step in the knowledge on tomato diversity with the so called "-omics" and next generation sequencing techniques is coming. 
These technologies and related data analysis allow a complete and combined reading of genomes and related levels of expression (transcriptome, proteome, metabolome) in a high throughput way. Among the new approaches, QTL mapping techniques in natural populations or genome wide association studies will facilitate the genetic characterization of complex traits and germplasm management of both wild and cultivated tomatoes.

In this chapter we will first show how tomato diversity evolved from its early domestication until today. We will discuss how valuable tomato genetic resources are, and that investigating natural variation not only highlights existing diversity -which is of critical use for cultivated tomato improvement- but can also provide insights into the evolution and genetic bases of complex traits. In the last part, we will present how molecular markers have completed our view.

\section{Diversity of the tomato clade species}

Tomato belongs to the large and diverse Solanaceae family also called Nightshades which includes more than three thousand species. Among them, major crops arose from Old world (Eggplant from Asia) and New world (pepper, potato, tobacco, tomato from South America). The Lycopersicon clade contains the domesticated tomato (Solanum lycopersicum) and its 12 closest wild relatives (Peralta and Spooner 2005). The radiation of tomato clade has been estimated to 7.8 (Nesbitt and Tanksley 2002) and to 2.7 Million years between $S$. lycopersicum and S. pennellii(Kamenetzky et al. 2010). First detailed studies on this group of wild relatives were made by Charles Rick and colleagues since the 40's. Tomato clade species are originated from the Andean region, including Peru, Bolivia, Ecuador, Colombia and Chile (Figure 1). On Figure 1, lycopersicon species distributions are defined according to geographic data from the Tomato Genetics Resource Center, UC Davis http://tgrc. ucdavis.edu/Data/Acc/dataframe.aspx? start=GIS_ dataoption. aspx\&navstart=nav.html. Their growing environments range from near sea level to 3,300 $\mathrm{m}$ altitude, from arid to rainy climate and from Andeans Highlands to the coast of Galapagos Islands (S. cheesmaniae; $S$. galapagense). Their habitats are often narrow and isolated valleys where they were adapted to particular microclimates and various soil types. Their very large range of ecological conditions contributed to the diversity of the wild species. This broad variation is also expressed at the morphological, physiological, sexual and molecular levels (Peralta and Spooner 2005). Over times, several phylogenetic classifications have been proposed and several adjustments occurred. Being first classified in the Solanum genus, the group turned to a specific genus, Lycopersicum (Miller, 1731). It recently got renamed Solanum within an updated classification (Peralta and Spooner 2001). Taxonomic, ecological, reproductive, breeding specificities for each member of the clade are listed in Table 1 and reviewed by Peralta and colleagues (Peralta, Spooner et al. 2007). The first classification was morphology based (Luckwill 1943). Later molecular data confirmed tomato membership of Linnaeus classification, but also improved subtaxa classification (Spooner 2008). The tomato clade is an interesting example for research on plant biodiversity, notably, on evolution, adaptation, human domestication and nutrition perspectives (Peralta and Spooner 2007). Nowadays, across South America, populations of wild tomatoes are being severely reduced. Their natural habitats are shrinking due to urban development and intensive agriculture as well as goat herding in the highlands, as recently documented by a botanical expedition in Peru. (Grandillo, Chetelat et al. 2011). 


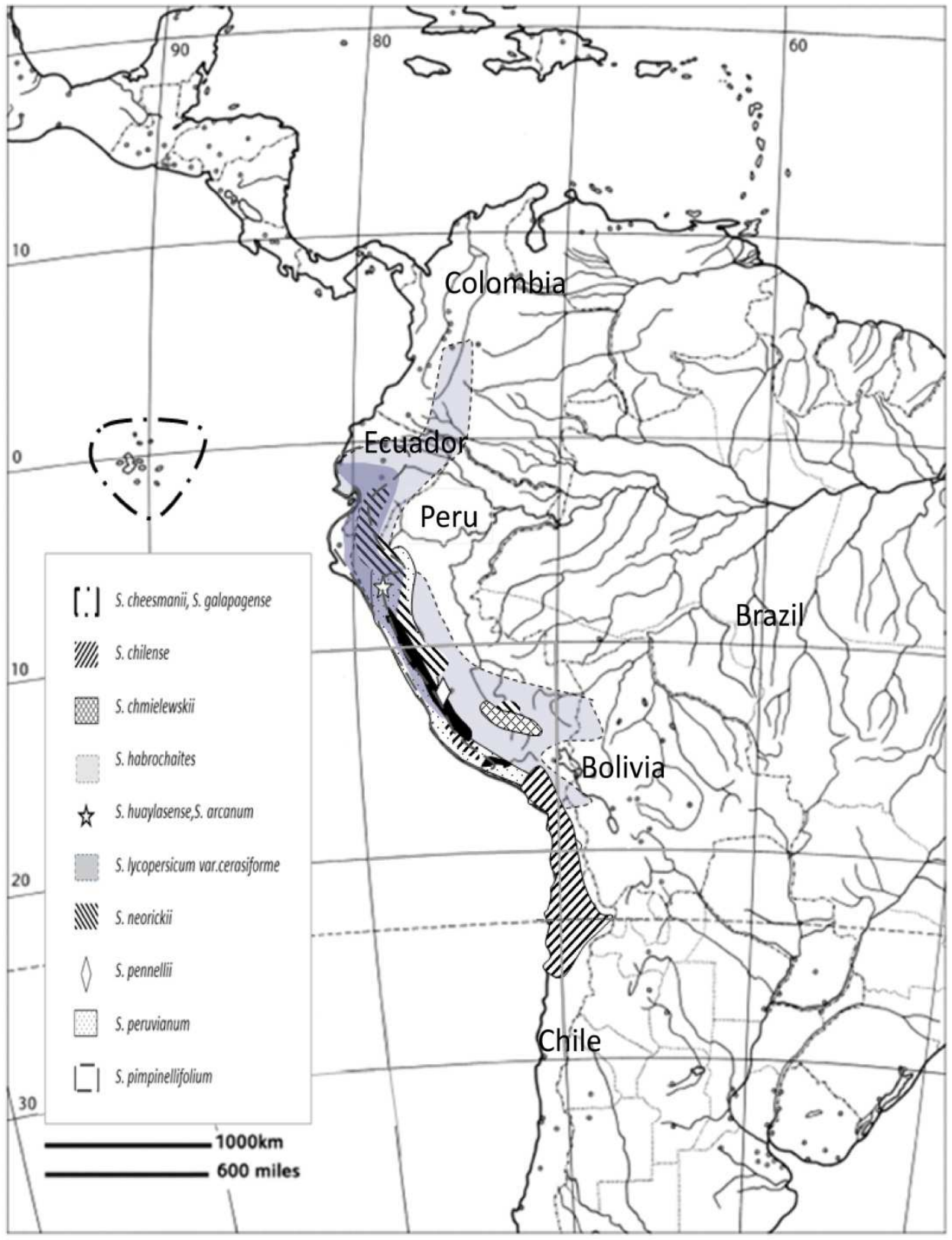

Fig. 1. Geographic distribution of wild species in Solanum section lycopersicon. 
Many studies were conducted on evolutionary aspects of the lycopersicon clade. The mating system was extensively studied, using the clade as a model to study its effects on species variation (Bedinger, Chetelat et al. 2011). Mating system has played a key role in evolution of wild tomatoes, varying from allogamous self-incompatible, to facultative allogamous, to autogamous and self-compatible (Table 1). Flower stigma exertion and gametophytic incompatibility system contribute in greater outcrossing and genetic diversity. All the species of the clade are intercrossable (Table 1), but with a variable success rate (Rick, Fobes et al. 1977a; Rick, Fobes et al. 1979). Fruit color discriminate the wild relative species. Most of the latter carry green fruits, with the exception of the two species from the Galapagos (with yellow and orange fruits) and S. pimpinellifolium, which is the only wild relative species with red fruits. S. pimpinellifolium fruits are round, small, weighing only few grams. These fruits are edible and the species referred as the currant tomato. The plant presents a reduced apical dominance and prostrate growth habit resulting in a large shrub with inflorescence carrying many flowers and fruits (Paran and van der Knaap 2007). S. pimpinellifolium undergone bottleneck only recently with a drastic reduction of its natural habitats and is now an endangered species (BiodiversityInternational 2006). S. lycopersicum var cerasiforme fruit is larger than S. pimpinellifolium and is commonly round and red. This subspecies of tomato is referred to as the "cherry tomato". It has been proposed as the direct ancestor of cultivated tomato because of its diversity, its wide spread occurrence in central America and its close genetic relationship with cultivated tomato (Rick and Chetelat 1995). The modern cultivated tomato, S. lycopersicum, is cosmopolite. It has spread all around the world and is now cultivated under a broad range of environments and conditions.

\section{Tomato domestication in South America}

Domestication is a special type of species diversification, distinct from species divergence through natural selection in the wild (Darwin and Wallace 1858). Domesticated species differ from wild and relative species for a set of traits known as the domestication syndrome (Doebley, Gaut et al. 2006). Domestication is often controlled by a limited number of chromosomal regions with major phenotypic effect (Purugganan and Fuller 2009). In tomato, edible fruits, attractive red color and fruit size increase are characterizing this process.

The domestication time of tomato is unclear. It is supposed to be due to a recent divergence from S. pimpinellifolium. The first hypothesis supports Peru as the center of origin and domestication (de Candolle 1882). This hypothesis gives emphasis on botanical evidences and has been complemented by botanical, linguistic and historical aspects. It was further supported by other colleagues (Müller 1940a; Müller 1940b; Luckwill 1943) and recent molecular studies (Nesbitt and Tanksley 2002). Nevertheless, very little and unclear archeological evidences are available to clearly support this hypothesis (McMeekin 1992). The second hypothesis supports that domestication occurred primarily in Mexico in the Vera Cruz Puebla area (Jenkins 1948), as there is no evidence for pre-Colombian cultivation of tomato in South America but good evidences in Mexico. Referring to Guilandini (1572), Jenkins also argued that tomato name comes most probably from the Mexican Nahua people word "Tomatl" that described "plants bearing globous and juicy fruit" (Sahagún 1988). Based on its 


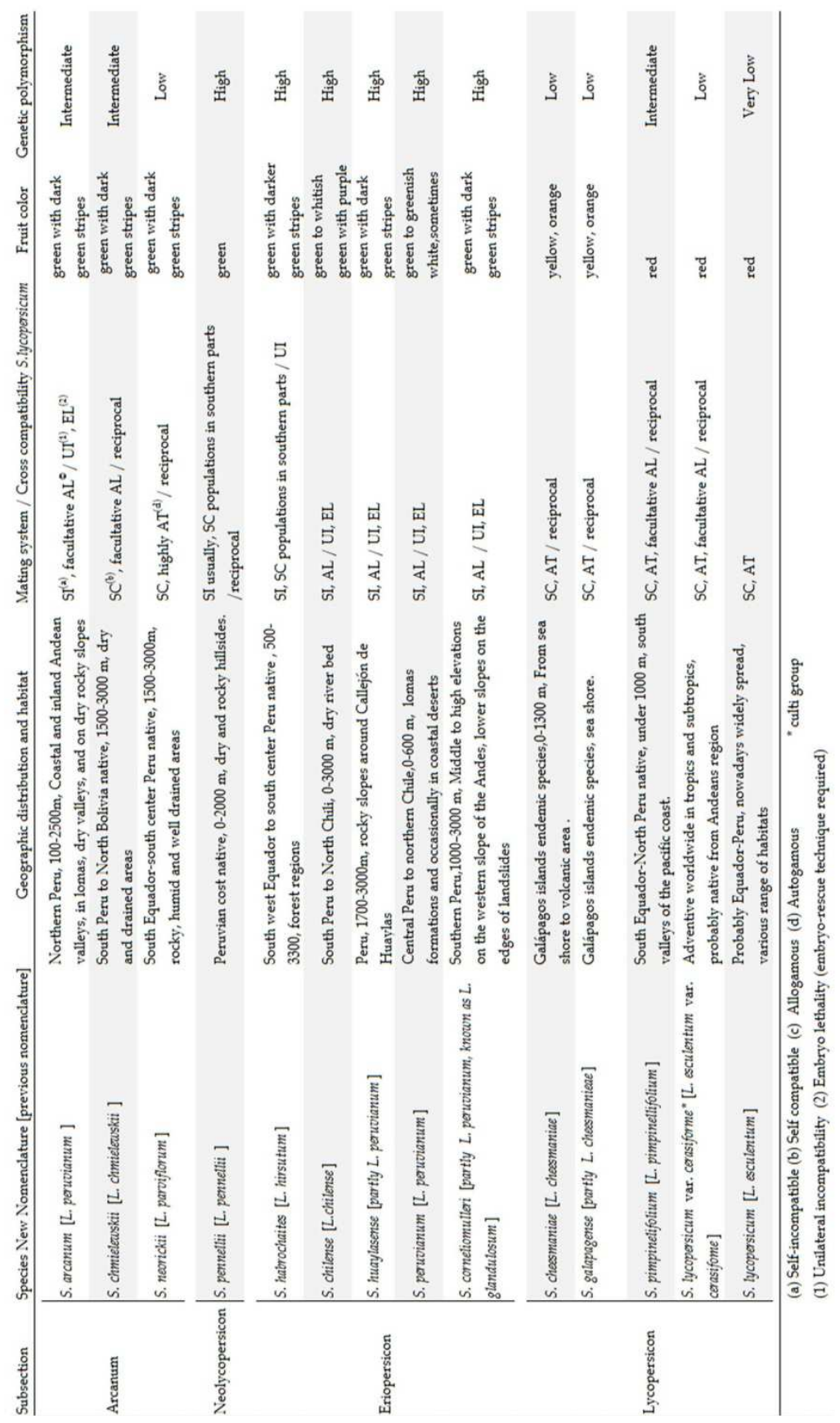

Table 1. Principal features of the lycopersicon subsection (Solanum sect. Lycopersicon) Data are compiled from Peralta et al. 2007, Moyle et al. 2008, Grandillo et al. 2011 
center theory, Harlan suggested that biloculed domesticated forms found in south Mexico and Guatemala are the oldest cultivated types (Harlan 1971). Quoting Sahagun, Diez argued that tomato was totally "integrated" in the Aztec civilization food consumption in XVI century, contrary to South American Incas (Diez and Nuez 2008). Nevertheless, two authors identified Quechua names possibly referring to tomato: "pirca" (Horkheimer 1973) and "pesco-tomate" (Yakovleff 1935). However, botanists consider the origins of tomato domestication as unsolved (Peralta and Spooner 2007b). These authors mention recent evidences showing that the Mexican hypothesis is not supported by comparative data, as South American and Mexican tomato accessions share similar isozymes (Rick and Fobes 1975) as well as molecular markers (Villand, Skroch et al. 1998). So far, no evidence appears to be enough conclusive and tomatoes may have been domesticated independently in both areas. To go further a more extensive analysis of molecular polymorphism in the wild and cultivated tomatoes is needed. This would allow investigating demographic scenarios and estimating the parameters of these scenarios (bottleneck intensity, ancestral population size, migration rates) using Markovian model implemented in tools such as $\mathrm{IM}^{*}$ program (Hey and Nielsen 2004) or $\mathrm{ABC}^{1}$ methodology (Beaumont, Zhang et al. 2002; Lopes and Beaumont 2010). Very recently, this approach has been implemented to infer past demography and ecological parameters of two tomato wild relatives, S. chilense and S. peruvianum (Tellier, Laurent et al. 2011).

Many authors consider S. lycopersicum var. cerasiforme as ancestral form of the cultivated tomato. It is present in both Mexico and Peru, on the contrary to S. pimpinellifolium which is absent from Mexico. If we assume that S.l. cerasiforme results from direct domestication from S. pimpinellifolium, a consequence of this domestication is that S.l. cerasiforme suffered a decrease of its population effective size during domestication (Bai and Lindhout 2007). Subsequent changes occurred for domestication traits such as growth habit, mating system, gigantism and fruit morphological diversity. Notably a change from exerted to inserted stigmas is responsible for the change from partial allogamy to strict autogamy. Selection for self-pollinating as well as shortening of the stigma compared to close wild relatives such as S. pimpinellifolium has allowed a yield increase (Rick 1977b). This "selfing syndrome" (Sicard and Lenhard 2011) is striking in tomato where a mutation in gene controlling stigma length has been identified in cultivated germplasm (Chen, Cong et al. 2007).

\section{Early cultivation in Europe and in the world}

Probably only a few tomato seeds were brought back from Mexico to Europe, leading, after domestication, to a new genetic bottleneck. George McCue has extensively reviewed the history of tomato diverse uses, tracking back the first references by country upon the time (McCue 1952). Most remote reference available comes from Petrus Matthiolus, an Italian Physician (1544). Due to its botanical closeness with toxic Solanum species common in Europe (Mandrake, Belladonna), tomato was for long mostly used as an ornamental. Two centuries later, it was referred as a cultivated plant in Italy by Saccardo (1769). Southern Europe was precursor in use of tomato for human consumption. In France, Bois at first mentions it as ornamental (1760). The same author reported it as vegetable seeds sold in the catalogue of the seeds of the "Maison grainière Andrieux Vilmorin" (1778). Lamarck mentioned it in 1798. Extensive consumption in Spain is described by Quer (1784).

\footnotetext{
${ }^{1}$ Approximate Bayesian Computation
} 
Progressively, following South-North gradient, tomato consumption reached Northern Europe (Sabine 1819). Similarly in USA, Bartram (1766) reported tomatoes being used as food plants. Boyd (1784) mentioned that The David Landreth Seed Co. started to sell tomato seeds for vegetable consumption. Selection for diverse fruit shapes and local adaptation probably rapidly occurred through bulk selection. The crop gained in economic importance by the end of XIXth century with the establishment of tomato breeding programs. Most of the plant material at that time can be considered as landraces: selected for subsistence agriculture environments, producing low but relatively stable yield. At the end of the XIX ${ }^{\text {th }}$ century, tomato cultivars (nowadays called landraces or heirlooms) were open pollinated from which seeds were saved by the farmers from a year to the other. Selection of new genotypes within heterogeneous cultivars (or selection of chance variance) resulted from spontaneous mutations, natural outcrossing or recombination of pre-existing genetic variation. Thus, S. lycopersicum found in Europe a secondary centre for diversification (García-Martínez, Andreani et al. 2006). In the XIXth century, establishment of commercial routes and colonies contributed to spread the species worldwide (Diez and Nuez 2008). In United States, prior to 1850 and "Trophy" the first commercially successful variety, no breeding programs were effective (Smith 2000). On an evolutionary perspective, domestication and implementation of breeding programs induced physiological changes. Artificial selection has reduced the genetic diversity of the crop which suffered a new bottleneck.

\section{Tomato breeding in the XXth century: Seeking for diversity and intensive production}

After domestication and adaptation to North hemisphere growing conditions for two centuries, the crop started the $X X^{\text {th }}$ century with benefits of two major scientific discoveries: The rediscovery of Mendel pioneering work to set up the basis of experimental methods on the use of plant hybridization (Mendel 1866). Second are established domestication concept (Darwin and Wallace 1858) and selection theory (Darwin 1859).

This context has seen the emergence in public institutes of plant germplasm banks, starting point for collecting existing genetic diversity, preserving and valorizing it, following the pioneer work of Nikolai Vavilov (1887-1943) (Kurlovich, Rep'ev et al. 2000). Later on, he was followed by Charles Rick (1915-2002) who dedicated his life to discover, collect and characterize exotic tomato germplasm (Tanksley and Khush 2002). Today, more than 83,000 tomato accessions are stored in seed banks worldwide, ranking $1^{\text {st }}$ among vegetable species collected (FAO 2010). The main collections in the world are: In USA, the Tomato Genetic Resources Center in California (TGRC), (www.tgrc.ucdavis.edu ) and the USDA 2 collection (www.ars.usda.gov), the World Vegetable Center in Taiwan (www.avrdc.org) and several Europeans collections. The establishment of tomato resource collections made major contributions to understand the distribution of its diversity around the world. Nevertheless the lack of coordination and conflicting passport data is a pitfall for an efficient tomato germplasm management. Efforts are now made to coordinate national initiatives in global or regional approaches. Since 2007, The European Cooperative Programme for Plant Genetic Resources (www.ecpgr.cgiar.org) is a collaborative project between most European countries for long-term conservation and utilization of plant genetic resources in Europe.

2 United States Department of Agriculture, Geneva 
This project is based on large network of national centers for tomato genetic resources including COMAV 3 (Spain), CGN 4 (Netherlands), INRA (France), IPK5 (Germany), Vavilov Institute (Russia) and others. These institutions share their germplasm informations through a database (http://documents.plant.wur.nl/cgn/pgr/tomato/). More recently, in the context of a European Solanaceae project (EU-SOL, www.eu-sol.wur.nl), a collection of more than 6,000 domesticated tomato accessions was established and phenotyped, accompanied by an ad hoc database (Finkers, de Weerd et al. 2011). Finally, since 2008, a world initiative, is conducted under the Plant Biodiversity Inventories (www.nhm.ac.uk/researchcuration/projects/solanaceaesource/). Project aim is to produce a worldwide taxonomic monograph of the species occurring within the plant genus Solanum. As well, tomato is part of long term collection of plant species project, launched by the Svalbard Global Seed Vault initiative (Food 2008).

Due to its broad use for food consumption and adaptation to many environmental conditions (from Alaska summers to tropical conditions) and different crop systems, tomato experienced an important phenotypic diversification. Hundreds of past and present cultivated varieties are now available. Cultivars are dedicated to two main markets, processing and fresh market. Processing tomatoes are cultivated as a field crop, whereas fresh market tomatoes are grown outdoor or indoor (heated and non-heated greenhouses). Breeding objectives have evolved over time, with the evolution of production systems. Nevertheless, three main objectives remain: adaptation to growth constraints, disease and pest resistances and fruit productivity and quality. Wild species were first used as source of adaptation to biotic stress. Disease resistance selection started in United States early $X^{\text {th }}$ century. The first fusarium wilt -resistant cultivar "Tennessee red" was released in 1912. Early 1920's breeders used hybridization with selection in segregating generations. By the mid-30's, plant breeders developed technical procedures to improve selection, such as pedigree selection. Later, existing or emerging private companies enhanced their development with the release of F1 hybrid varieties. Selection for disease resistance was successful as dominant resistance genes were found in the wild relatives for most of the diseases and pests. Modern cultivars can cumulate up to 12 different disease resistance genes which all derive from wild species. Wild germplasm has been primarily used as a source of major resistances.

Processing tomato industry was developed to provide North American and European households canned tomato, tomato paste and ketchup. Processing tomato varieties differ from fresh market ones in their pulp volume. Their growing conditions are dramatically different from fresh tomatoes (open field, mechanical harvesting). Thus the main criteria for processing tomatoes are fruit firmness, plant type with short fruit set period to produce a high percentage of ripe fruits simultaneously. Compact fruit set was obtained from a natural mutation discovered at the beginning of the $X X^{\text {th }}$ century, named $s p$ (for self-pruning), conferring to the plant a determinate growth. This mutation was introduced in the well known "Roma" variety, whose long fruit type became a specific trait in processing tomatoes. In the 60 's, VF145 was the first variety mechanically harvested. This cultivar has been the major cultivar for tomato ketchup industry for more than a decade in California. Apart from $s p$, several other mutations (detected in cultivated tomato or through interspecific

${ }^{3}$ Centro de Conservación y Mejora de la Agrodiversidad Valenciana, Valencia

${ }^{4}$ Center for Genetic resources, Wageningen

${ }^{5}$ Institut für Pflanzengenetik und Kulturpflanzenforschung, Gatersleben 
hybridization) were used in tomato breeding. For example, the jointless (Szymkowiak and Irish 2005; Quinet, Kinet et al. 2011) j2 allele was introgressed from S. Cheesmanii. In combination with $s p, j 2$ has been bred into many processing varieties, allowing a large scale mechanical harvest of tomato fruits. Major genes used in tomato breeding are listed in Table2.

Today, after a rapid evolution towards very firm fruits and long shelf life varieties (with the major success of the variety Daniela, which carried the spontaneous rin mutation), consumers request more diverse texture and tastes (Causse, Friguet et al. 2010). The fresh tomato market faces rapid developments and diversification (Navez 2011). New products and varieties are emerging always faster and their life cycle gets shorter, 5 years in average (Bai and Lindhout 2007). Consumption trend is for broader and diverse choice of fruit types. After the development of truss and cherry type tomatoes, new cultivars resembling to old heirloom varieties are developed. If access to allelic diversity is a must to improve fruit quality, choices in breeding objectives are critical to maintain organoleptic fruit values. Strong associations are often made by consumers between morphology and sensory values. Association of "Oxheart" or "Marmande" fruit shape with a pleasant texture is a good example. This link can be lost through modern breeding (Casals, Pascual et al. 2011). Improved content in potential health beneficial components such as anti-oxidants (lycopene, vitamin C) is also promoted. This can be obtained thanks to specific mutations like $h p$ (Lieberman, Segev et al. 2004) or, again, by the introgression of genes from wild relatives.

Farmers and breeders have shaped diversity over years in an ever-evolving process that is hard to track and to record. Intensive breeding of crop varieties by modern science has increased the genetic erosion which started with domestication. Nevertheless the introgression from wild relatives allowed major progress and introduced a new source of diversity. Charles Rick observed that crosses between wild and cultivated species generated a large diversity of novel phenotypic diversity. Rick's work represents milestones for the modern use of genetic diversity in tomato. It led to uncover positive transgressive variation within interspecific progenies. This encouraged a greater use of exotic germplasm and thus larger gene pools to unlock causal polymorphism.

\section{Biotechnology as a source of new diversity}

Many natural mutants discovered in cultivated tomato have been extensively studied and characterized (http://tgrc.ucdavis.edu/), but their amount is limited. Thus reverse genetic techniques were developed aiming to discover gene function by analyzing the phenotypic effects of specific variants of targeted gene sequence. This approach is complementary to classical ("forwards") approaches, as they allow silencing or promoting the expression of targeted gene. They can also be used to generate genetic diversity within DNA sequences.

A delayed ripening tomato, named Flavr-savr ${ }^{\circledR}$ tomato, with a reduced expression of a cell wall protein (a polygalacturonase), obtained by an antisense construction, was the first transgenic plant released on the fresh market (Kramer and Redenbaugh 1994; Sanders and Hiatt 2005). This transformation significantly improved fruit shelf life and storage quality. Nevertheless, it was a commercial failure. Few years later, consumer's concerns about GMO6,

${ }^{6}$ Genetically Modified Organism 


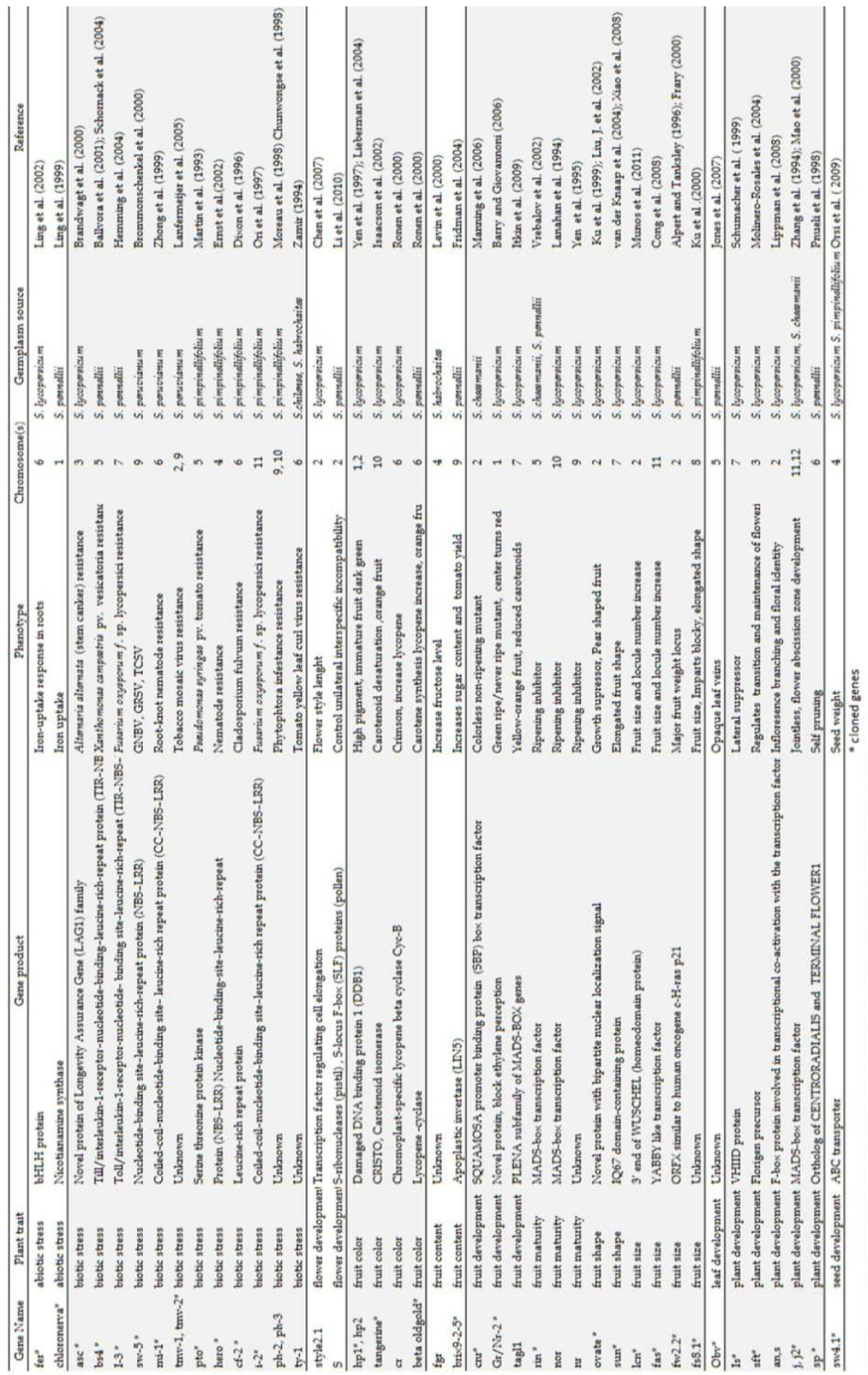

Table 2. List of genes characterized through molecular techniques with their related function and germplasm origin 
as well as the high engineering cost, stopped further commercial developments. In the research field, transformation with Agrobacterium thumefaciens is still widely used for the functional characterization of specific genes. For instance, transformed tomato plants were produced to enable study of endotoxins genes (Zhang, Buehner et al. 2006) plant disease resistance genes, abiotic stress genes or to produce molecules useful in human medicine (Sharma, Singh et al. 2008).

TILLING (Target Induced Local Lesion In Genomes), a mutagenesis technique, has experienced important development (Comai and Henikoff 2006). Early days of this technique were in the 50's (Rick 1991). It is now widely used for reverse genetics to generate and identify induced point mutations in genomes. A chemical reagent (Ethylmethane Sulphonate) is used to induce genetic mutations. Collections of tomatoes carrying artificially induced genetic variants, called mutant libraries are currently available (Menda, Semel et al. 2004; Minoia et al. 2010) or under development (Okabe, Asamizu et al. 2011). In contrast to transgenic methods, mutagenesis is random, cost effective and is not submitted to GMO regulation. TILLING allows generating variants in cultivated genetic background (Piron, Nicolaï et al. 2010) and thus transfer rapidly interesting mutations into cultivars (Gady, Hermans et al. 2009). Application of TILLING technique to screen for natural variation within tomato germplasm collection is now performed (Rigola, van Oeveren et al. 2009).

\section{Molecular markers offer a new vision of tomato diversity}

Natural genetic diversity is the fuel of evolution. No evolutive forces or adaptation to environment changes can apply without it (Alonso-Blanco, Aarts et al. 2009). Consequently it is a vital characteristic for species adaptation in general and for crop breeding in particular. Genetic variation occurs both within cultivated tomato (intraspecific) and between wild species (interspecific). Tomato breeding for adaptation to specific growing areas is in progress for more than two centuries now (Stevens and Rick 1986). Since the early days of quantitative genetics, initiatives were developed to improve the understanding of trait inheritance. Attempts to construct genetic maps based on interspecific crosses (S. pimpinellifolium $\times$ S. lycoperpersicum) and to map disease resistance genes are performed for years (Langford 1937). A linkage map showing the distribution of agronomic trait with Mendelian inheritance, based on linkage between two or three mutations, was proposed (Butler 1952). Nevertheless, the lack of polymorphic and neutral markers was strongly limitant. Development of isozymes allowed a first evaluation of wild germplasm (Rick and Fobes 1975) and introgression diagnostic (Tanksley, Medina-Filho et al. 1981), but isozyme marker scarcity and their low polymorphism was still limitant. This limitation was progressively overcome since the 80 's thanks to the discovery of several molecular marker types.

\subsection{Ecological and evolution in wild tomato related species}

Molecular studies provide important clues into ecological and evolutionary questions in wild tomatoes species. In speciation process, hybrid sterility is frequently due to dysfunctional interactions between loci that accumulate between different lineages. A "snowballing effect" characterizes loci controlling such reproductive barrier and hybrid sterility that should accumulate faster than linearly with time. Such "snowballing" effect has been recently described within distinct populations derived from crosses of S. lycopersicum with S. pennellii, 
S. habrochaites and S. lycopersicoides (Moyle and Nakazato 2010). However, further investigations are suggested to confirm these results (Stadler, Florez-Rueda et al. 2011).

Tellier and colleagues quantified the number of adaptive and deleterious mutations and the distribution of fitness effects of new mutations within housekeeping genes in 4 species, $S$. arcanum, S. chilense, S. habrochaites and S. peruvianum. Little evidence for adaptive mutations was shown but strong purifying selection in coding regions was detected (Tellier, Fischer et al. 2011). This suggests that closely related species with similar genetic backgrounds but contrasted environments differ in the frequency of deleterious fitness effects.

The west coastal area between the Andes and the ocean, from Ecuador to Chile is widely recognized as the center of origin of the species from the Solanum sect. lycopersicon. This area covers a wide range of geographical conditions. Complex geography and ecology of Andes had a major impact in species divergence and hybridization between $S$. pimpinellifolium and S. lycopersicum (Nakazato and Housworth 2011). The two species present a distinct lineage, separated by the Andes. They hybridize extensively in north and central Ecuador. Nakazato and colleagues demonstrated using molecular markers and geographic information system (GIS) data that S. lycopersicum has likely experienced a severe population bottleneck during the colonization of the eastern Andes followed by a rapid population expansion. In plant, resistance genes and homologs (RGA) tend to be highly variable. Caicedo et al (2004) studied the geographic distribution of a RGA family Cf2 (see Table 2) within and among plant populations of S. pimpinellifolium. They underlined that the geographical distribution of RGA diversity has been primarily shaped by demographic factors and selective pressure (Caicedo and Schaal 2004; Caicedo 2008). The authors underlined the reduction of natural habitat. This phenomenon is also observed on Galapagos Islands. The endemic species $S$. cheesmanii shows a reduction of its population due to human activity. Differentiation within $S$. cheesmanii was also observed (Nuez, Prohens et al. 2004) as well as hybridization with the two introduced species S. lycopersicum and S. pimpinellifolium (Darwin, Knapp et al. 2003).

\subsection{Diversity analysis among wild and cultivated germplasm}

Allelic richness (number of different alleles segregating in the population) is used to measure the genetic diversity and is considered as a key parameter for genetic resources management. It reveals past fluctuations in population size (Nei, Maruyama et al. 1975). Molecular differences between more than 200 Peruvian and Ecuadorian S. pimpinellifolium accessions were highlighted by Zuriaga and colleagues. Climate and genetic data were highly correlated. Thus the non-uniform nature of climates between the two countries is shown to be an important factor. Highest diversity was found in North Peru, lowest on Galapagos Islands. Authors stressed the fact that interspecific variation between $S$. pimpinellifolium and S. lycopersicum was indicating a very close relatedness between the two species (Zuriaga, Blanca et al. 2009).

Cherry tomato accessions show typically a large genetic diversity and an intermediate fruit size between S. pimpinellifolium and large cultivated ones. Botanists postulate that cherry tomato accessions are feral plants (also called revertant) or a possible genetic admixture of wild and cultivated germplasm (Rick and Holle 1990; Peralta et al. 2007a). Recently molecular analysis of the structure of a large set of accessions of wild S. pimpinellifolium, cherry tomato and cultivated accessions showed that domesticated and wild tomatoes have 
evolved as a species complex with intensive hybridization. This highlighted the admixture position of S. lycopersicum var. cerasiforme (Ranc, Muños et al. 2008) which is illustrated on figure 2 using a data from Ranc et al (2010) and analyzed using Structure 2.0 (Pritchard et al. 2000) output data. Accessions display clustering patterns (circled) following two phenotypic traits: fruit size and stigma insertion. Structuration effect of those domestication traits can be observed. The emergence of molecular markers has allowed quantifying with accuracy the diversity within germplasm material. The first molecular diversity studies on cultivated tomato revealed the very low polymorphism compared to wild species, whether it was based on RFLP7 (Miller and Tanksley 1990), SSR ${ }^{8}$ (Bredemeijer, Cooke et al. 2002; He, Poysa et al. 2003) AFLP9 9 (Park, West et al. 2004; Berloo, Zhu et al. 2008), SSAP10 (Tam, Mhiri et al. 2005) or SNP11 (Yang, Bai et al. 2004; Labate and Baldo 2005). However, Bredemeijer et al (2002) characterized 500 cultivated lines from European lines and showed that it was possible to distinguish them all from each other using a set of 20 SSR markers. When comparing old varieties (or landraces) to modern hybrids, a higher level of molecular diversity in landraces is usually observed (Mazzucato, Papa et al. 2008; van Berloo, Zhu et al. 2008).

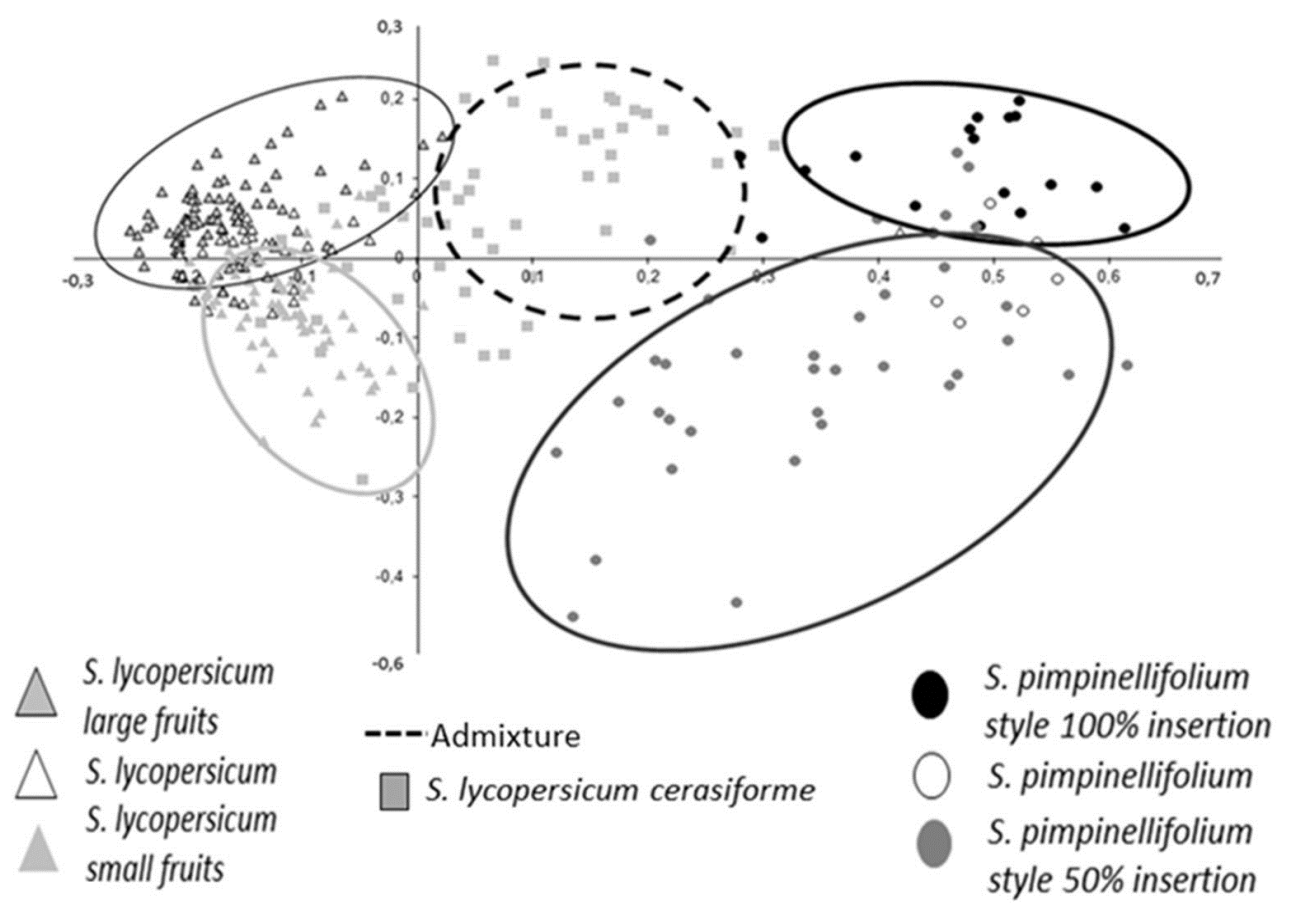

Fig. 2. Principal Coordinate Analysis of 318 accessions tomato core collection.

\footnotetext{
7 Restriction Fragment Lenght Polymorphism

8 Simple Sequence Repeats

9 Amplified Fragment Lenght Polymorphism

10 Sequence-Specific Amplification Polymorphism

11 Single Nucleotide Polymorphism
} 
If interspecific populations for genetic analyses and diversity studies answered to many questions, it has left a void in the understanding of genotypic variation within tomato breeding programs which focus on intra-specific populations (Van Deynze, Stoffel et al. 2007). The recent discovery of SNP markers, first detected in EST (expressed sequenced tag) sequences (Van Deynze et al. 2007; Jimenez-Gomez and Maloof 2009) then in non-coding sequences (Labate et al. 2009) provided access to a higher level of polymorphism. Labate and colleagues estimated parameters of diversity among S. lycopersium accessions, first using the SNP detected in 50 loci that were resequenced in a diversity panel of 31 accessions. In a second investigation, multilocus estimates of polymorphism were obtained and led to rejection of the neutral equilibrium model of evolution within the studied collection (Labate, Robertson et al. 2009). Public germplasm are potential allele mining sources for crop improvement as illustrated by previous authors who sampled among US seed banks 30 accessions from the five continents. The study confirmed that history of crossing with wild tomato species and distribution among different environments across the world has spread allelic variation (Labate, Sheffer et al. 2011).

Molecular markers have proven their efficiency in sampling and maximizing allelic richness (Schoen and Brown 1993) through the development of nested core collections (McKhann, Camilleri et al. 2004). Such nested core collections (from 8 to 96 accessions) were constructed in tomato, capturing most of the molecular and phenotypic variation present in a set of 360 constituted of wild, feral and cultivated accessions (Ranc, Muños et al. 2008).

\subsection{Use of molecular diversity to dissect phenotypes}

Molecular markers allowed the construction of high density genetic maps of the tomato genome (Tanksley, Ganal et al. 1992). This permitted the dissection of quantitative traits into Mendelian factors or QTL (Quantitative Trait Loci) (Paterson, Lander et al. 1988; Tanksley et al. 1992). This strategy also opened the way to investigate physical mapping and molecular cloning of genetic factors underlying quantitative traits (Paterson, Damon et al. 1991). Moreover, Lycopersicon varieties and related species are all diploid and chromosomally collinear, making genetic dissection straightforward. The first gene cloned by positional cloning was the Pto gene, confering resistance to Pseudomonas syringae (Martin, Brommonschenkel et al. 1993). Since then, interspecific crosses with each wild species were performed. Due to the low genetic diversity within the cultivated compartment (Miller and Tanksley 1990), most of the mapping populations are based on interspecific crosses between a cultivar and related wild species from the lycopersicon group (as reviewed by Foolad (2007) ;Labate, Grandillo et al.(2007); Grandillo et al (2011)) or from lycopersicoides (Pertuzé, Ji et al. 2002) and juglandifolia group (Albrecht, Escobar et al. 2010). However, maps based on intraspecific crosses have proved their interest notably on fruit quality aspects (SalibaColombani, Causse et al. 2001). All those populations allowed discovering and/or characterizing a myriad of major genes (Table 2) and QTLs involved in various traits.

Rapidly, molecular breeding strategies were set up and implemented to "pyramid" genes of interest for agronomical traits, notably using Advanced Backcross QTL method (ABQTL) (Tanksley, Grandillo et al. 1996). Using this approach with a S. lycopersicum $x$ S. pimpinellifolium progeny, in which agronomical favorable QTL alleles were detected, Grandillo and colleagues showed how a wild species could contribute to improve 
cultivated tomato (Tanksley, Grandillo et al., 1996). Introgression Lines (IL) derived from interspecific crosses allowed to dissect the effect of chromosome fragments from a donor (usually from a wild relative) introgressed into a recurrent elite line. IL offer the possibility to evaluate the agronomic performance of a specific set of QTL (Paran, Goldman et al. 1995). IL was used as a base for fine mapping and positional cloning of several genes and QTL of interest. The first IL library was developed between S. pennellii and S. lycopersicum (Eshed and Zamir 1995; Zamir 2001). QTL mapping power was increased compared to biallelic QTL mapping population, and was again improved by the constitution of sub-IL set with smaller introgressed fragments. This progeny was successful in identifying QTLs for fruit traits (Causse, Duffe et al 2004); anti-oxidants (Rousseaux, Jones et al. 2005), vitamin C (Stevens, Buret et al. 2007) and volatile aromas (Tadmor, Fridman et al. 2002). The introgression of a QTL identified in these IL has allowed plant breeders to boost the level of soluble solids (brix) in commercial varieties and largely increased tomato yield in California (Fridman, Carrari et al. 2004). Such exotic libraries were thus designed with several species, involving S. pimpinellifolium (Doganlar, Frary et al. 2002), S. habrochaites (Monforte and Tanksley 2000; Finkers, van Heusden et al. 2007) and S. lycopersicoides (Canady, Meglic et al. 2005).

Introgression lines were also used to dissect the genetic basis of heterosis (Eshed and Zamir 1995). Heterosis refers to phenomenon where hybrids between distant varieties or crosses between related species exhibit greater biomass, speed of development, and fertility than both parents (Birchler, Yao et al. 2010). Heterosis involves genome-wide dominance complementation and inheritance model such as locus-specific overdominance (Lippman and Zamir 2007). Heterotic QTL for several trait were identified in tomato IL (Semel and Nissenbaum, 2006). A unique QTL was shown to display at the heterozygous level improved harvest index, earliness and metabolite content (sugars and amino acids) in processing tomatoes (Gur, Osorio et al. 2010; Gur, Semel et al. 2011) Furthermore, a natural mutation in the SFT gene, involved in flowering (Shalit, Rozman et al. 2009), was shown to correspond to a single overdominant gene increasing yield in hybrids of processing tomato (Krieger, Lippman et al. 2010).

Metabolite detection is an approach of choice to identify compounds involved in fruits quality traits. Metabolite QTL (mQTL) can be now identified for non-volatile metabolites like sugars, pigments or volatiles compounds (Bovy, Schijlen et al. 2007). This was done on several interspecific populations, notably on S. lycopersicum $x$ S. Chmielewskii (Do, Prudent et al. 2010) and intraspecific crosses (Saliba-Colombani et al. 2001; Causse, SalibaColombani et al. 2002; Zanor, Rambla et al. 2009). Recent technologies allowed screening for diversity in a wide range of components on whole genomes. This can be done in a targeted way to better characterize known metabolites (Tieman, Taylor et al. 2006) or untargeted manner to identify new metabolites (Tikunov, Lommen et al., 2005). Further than identify and quantify compounds, metabolomics can be of great help to decipher biosynthetic pathways (Keurentjes 2009). Metabolome studies can be combined to transcriptomic data to identify the key factors (Mounet, Moing et al. 2009; Do, Prudent et al. 2010). Metabolomics has an important role to play in characterization of natural diversity in tomato (Schauer, Zamir et al. 2004; Fernie et al. 2011). As well, it can boost the biochemical understanding of fruit content and be an enhancer for quality breeding (Fernie and Schauer 2009; de Vos, Hall et al. 2011). 


\subsection{Dissection of the molecular bases of domestication and diversification}

Product of human domestication and later diversification of fruit types, led to a large morphological diversity in tomato fruit (with small to large, round, blocky, elongated, pear shaped fruits, with color ranging from red to green, white, black, pink, orange or yellow). On the contrary, wild tomato species carry small, round red or green fruits, with a low intraspecific phenotypic diversity. This has drawn scientist attention on the inheritance and development of fruit size and shape in the tomato (Yeager 1937). Influence of chromosome 2 in fruit morphology was noticed (Butler 1964). Thus, using available molecular techniques, fruit traits genetic control has been widely dissected (Grandillo, Ku et al. 1999; Lippman and Tanksley 2001; Barrero and Tanksley 2004). The first QTL, fw2.2, controlling fruit weight variation was cloned (Frary, Nesbitt et al 2000). It has been suggested that diversity of fruit shape in cultivated germplasm can be explained to a large extent by four genes (Rodriguez, Muños et al. 2011). The study established a model for fruit shape evolution in tomato. This model includes four major mutations recently identified: FAS which increases locule number, fruit fasciation and size (Cong, Barrero et al. 2008), LC which increases locule number and fruit size (Muños, Ranc et al. 2011), OVATE which gives ovoid fruit shape (Liu, van Eck et al 2002) and SUN which gives an elongated fruit shape (van der Knaap, Lippman et al. 2002; Xiao, Jiang et al. 2008) or the oxheart shape when associated to LC and FAS. The allelic distribution of the four genes was associated with morphologic, geographical and historical data in a collection of diverse cultivated accessions. This study established that the selection occurred in distinct chronologic and historic periods: LC arose first, followed by OVATE, both in S.l. cerasiforme background but in distinct populations. FAS arose later in a LC background. Presence of those three mutations in Latin American germplasm suggests Pre-Columbian mutations. Combined with fw2.2, they must have strongly contributed to the increase in fruit size during tomato domestication. On the contrary, SUN mutation is not carried by any Latin American material tested, suggesting that SUN mutation appeared post domestication in European material (probably in Italy). This study also showed that the selection for fruit shape is strongly responsible for the underlying genetic structure in tomato cultivars. The recent discoveries of the molecular events shaping tomato fruit indicate that the germplasm is frequently more diverse phenotypically than the wild related germplasm but not necessarily showing a similar pattern at the molecular level. "The irony of all this," says Steve Tanksley (geneticist at Cornell University, and precursor of all these studies) "is all that diversity of heirlooms can be accounted for by a handful of genes. There are probably no more than 10 mutant genes that create the diversity of heirlooms you see" (Borrell 2009). Tomato selection and spread worldwide has led to the immense diversity of varieties that characterizes many domesticated plant species (Purugganan and Fuller 2009).

\section{Association genetics: New valorization of natural diversity}

Recent advance in molecular genetics and computation has allowed the emergence of association mapping (Myles, Peiffer et al. 2009). Association mapping takes advantage of historical recombination events and natural genetic diversity. By using large numbers of lines and molecular markers over the whole genome, the resolution of Genome Wide Association studies (GWAS) is much higher than in conventional segregating populations. Such approach requires an accurate estimate of the genetic structure of the sample studied (Price, Zaitlen et al. 2010) and linkage disequilibrium (LD) extend among loci. Yu and 
colleagues (2005) proposed a unified mixed model taking into account the genetic structure of the sample, based on single locus analysis. This model is being updated by integrating a multi-locus analysis (Ayers et al. 2010).In autogamous crops, it is expected that large extent of LD will reduce the resolution and risks to lead to false positive associations. Nevertheless, successful results have been obtained in selfing crops (Atwell, Huang et al. 2010; Ramsay, Comadran et al. 2011).

In tomato, several studies revealed contrasted results according to the samples studied. First studies of the linkage disequilibrium revealed large LD in cultivated tomatoes (Mazzucato, Papa et al, 2008; van Berloo, Zhu et al, 2008; Robbins, Sim et al, 2010). Van Berloo and colleagues performed association mapping within a collection of 94 accessions containing both old and elite (hybrids) European germplasm and about 300 markers (AFLP). Structure coinciding with fruit size was identified allowing grouping between cherry tomato and round-beef types, extensive LD was observed (15 cM average). Robbins and colleagues investigated the population structure among 70 tomato cultivars (modern and vintage, from fresh and processing market). The STRUCTURE analysis (Pritchard, Stephens et al. 2000) revealed groups predefined by market niche and age into distinct subpopulations. Furthermore, they detected two subpopulations within the processing varieties, corresponding to historical patterns of breeding conducted for specific production environments. They found no subpopulation within fresh-market varieties. High levels of admixture were shown in several varieties representing a transition in the demarcation between processing and fresh-market. Mapping and LD analysis on a genome wide level was performed (Robbins, Sim et al. 2010). Using a panel of 102 accessions including 95 cultivars (heirloom, fresh and processing cultivars) and 9 wild species), effect of selection on genome variation was studied using 340 markers (SNP, SSR, and INDEL ${ }^{12}$ ). LD value varied from 6-8 cM (all accessions) up to 3-16 cM (fresh market cultivars). Inter-chromosomal LD appeared to be population dependent, suggesting cautious approach for association mapping. Notably, a genetic divergence between fresh market and processing types was also shown. On the contrary, the use of cherry tomato allowed the construction of core collection with a reduced structure and lower LD (Ranc et al, 2008; 2010). In a pilot study on chromosome 2, using markers distant from several cM to few kb, Ranc (2010) showed that LD varied strongly from one region to the other. A few distant markers remained in strong LD, but could be removed from the analysis.

The first association study was performed by Nesbitt and Tanksley (2002) to identify the SNP responsible for FW2.2 gene they had cloned. They failed to find any association between fruit size and genomic sequence of the fw2.2 region in a collection of 39 cherry tomato accessions. Ranc and colleagues (2010) identified significant association in the promoter region, thanks to a larger and more representative sample. From a breeding point of view, the admixture mapping between the cultivated tomato and its closest relative is a method of choice for allele mining in wild germplasm. Muños and colleagues (2011) used this approach to identify causal polymorphism of QTL controlling locule number on chromosome 2. New SNP arrays are now available thanks to Next Generation Sequencing technologies (NGS), as the genotyping array developed under the Solanaceae Coordinated Agriculture Project (SolCAP) initiative carrying 7,000 effective SNP (SolCAP 2008). These tools will be very useful to scan the whole genome for associations.

\footnotetext{
12 Insertion-Deletion
} 


\section{Conclusion: Toward a change in the way to manage and use diversity}

Crossing wild and cultivated species can reveal alleles left behind during the domestication process. Molecular markers strongly helped to reinforce the use of wild relatives (Zamir 2008). Interfacing genetic resources management and plant breeding, pre-breeding is now recognized as an important adjunct to plant breeding, as a way to introduce new traits from non-adapted populations and wild relatives, notably for abiotic stress (FAO 2010). Nevertheless, the extensive use of this genetic richness contained in seed banks and germplasm collection faces limits. The difficulty to introgress accurately the targeted allele (with favorable effect) without unfavorable ones, carried on by "linkage drag", remains.

With the emergence of bioinformatics and nanotechnologies -so called "post-genomics" erathe last decade has opened high throughput sequencing era. Now, conducting large intraspecific studies becomes a reality in tomato, allowing a better characterization of its genetic diversity. With the completion of its genome sequence (Mueller, Lankhorst et al. 2009) and rich annotation as well as a large number of tools available via SGN (SOL Genome Network; http://solgenomics.net/organism/solanum_lycopersicum/genome) platform (Bombarely, Menda et al. 2010), tomato and its relatives is the most advanced vegetable crop. A draft of the genome sequence of S. pimpinellifolium LA1589 is also released by D. Ware, W. R. McCombie, and Z. B. Lippman at Cold Spring Harbor Laboratory allowing a detailed comparison of both species. The genome sequences of tomato provide clues for understanding the Solanum clade evolutive history and identify genes involved in fleshy fruit development.

Progress in sequencing technologies has reached the point where genotyping by sequencing (GBS) is now possible (Davey, Hohenlohe et al. 2011; Elshire, Glaubitz et al. 2011). This opens new perspectives in terms of genetic diversity management, notably toward conservation and survey of large populations. In a near future, techniques such as GBS may allow breeders and scientists of the tomato community to determine population characteristics prior concretely establishing genome or nucleotide diversity. GBS opens ways to a global and quantitative management of diversity, and let foresee an a priori genetic resource management. It also opens perspectives in allele based breeding called genomic selection (Hamblin, Buckler et al. 2011).

If ex situ germplasm conservation is well developed and will benefit of these developments, in situ conservation of tomato and its wild relatives is becoming critical due to major ecological changes in its area origin. Efforts on in situ conservation and participatory approaches as proposed by Jarvis, Brown et al (2008) and (Thomas, Dawson et al. 2011) could be very useful to maintain the adaptive potential of tomato genetic resources. Nuez and colleagues proposed to use $S$. cheesmanii accessions now stored in germplasm banks to reinstate some extinct populations in Galapagos Islands (Nuez et al. 2004). This could help avoiding the present paradox: the more knowledge we gain on tomato diversity and its evolutive history, the less available those genetic resources are available in the wild.

\section{References}

Albrecht, E., M. Escobar, et al. (2010). "Genetic diversity and population structure in the tomato-like nightshades Solanum lycopersicoides and S. sitiens." Annals of Botany 105(4): 535-554. 
Alonso-Blanco, C., M. G. M. Aarts, et al. (2009). "What Has Natural Variation Taught Us about Plant Development, Physiology, and Adaptation?" The Plant Cell Online 21(7): 1877-1896.

Atwell, S., Y. S. Huang, et al. (2010). "Genome-wide association study of 107 phenotypes in Arabidopsis thaliana inbred lines." Nature 465(7298): 627-631.

Ayers, K. L. and H. J. Cordell (2010). "SNP Selection in genome-wide and candidate gene studies via penalized logistic regression." Genetic Epidemiology 34(8): 879-891.

Bai, Y. and P. Lindhout (2007). "Domestication and Breeding of Tomatoes: What have We Gained and What Can We Gain in the Future?" Annals of Botany 100(5): 1085-1094.

Barrero, L. S. and S. D. Tanksley (2004). "Evaluating the genetic basis of multiple-locule fruit in a broad cross section of tomato cultivars." Theoretical and Applied Genetics 109(3)): 669-679.

Barry, C. S. and J. J. Giovannoni (2006). "Ripening in the tomato Green-ripe mutant is inhibited by ectopic expression of a protein that disrupts ethylene signaling." Proceedings of the National Academy of Sciences 103(20): 7923-7928.

Beaumont, M. A., W. Zhang, et al. (2002). "Approximate Bayesian Computation in Population Genetics." Genetics 162(4): 2025-2035.

Bedinger, P., R. Chetelat, et al. (2011). "Interspecific reproductive barriers in the tomato clade: opportunities to decipher mechanisms of reproductive isolation." Sexual Plant Reproduction 24(3): 171-187.

Berloo, R., A. Zhu, et al. (2008). "Diversity and linkage disequilibrium analysis within a selected set of cultivated tomatoes." Theoretical and Applied Genetics 117(1): 89-101.

Biodiversity-International (2006) "Crop wild relatives." 25.

Birchler, J. A., H. Yao, et al. (2010). "Heterosis." The Plant Cell Online 22(7): 2105-2112.

Bombarely, A., N. Menda, et al. (2010). "The Sol Genomics Network (solgenomics.net): growing tomatoes using Perl." Nucleic Acids Research 39(Database): D1149-D1155.

Borrell, B. (2009). "How to Grow a Better Tomato: The Case against Heirloom Tomatoes." Scientific American http://www.scientificamerican.com/article.cfm?id=case-against-heirloomtomatoes

Bovy, A., E. Schijlen, et al. (2007). "Metabolic engineering of flavonoids in tomato (Solanum lycopersicum): the potential for metabolomics." Metabolomics 3(3): 399-412.

Brandwagt, B. F., L. A. Mesbah, et al. (2000). "A longevity assurance gene homolog of tomato mediates resistance to Alternaria alternata f. sp. lycopersici toxins and fumonisin B1." Proceedings of the National Academy of Sciences 97(9): 4961-4966.

Bredemeijer, M., J. Cooke, et al. (2002). "Construction and testing of a microsatellite database containing more than 500 tomato varieties." Theoretical and Applied Genetics 105(6-7): 1019-1026.

Brommonschenkel, S. H., A. Frary, et al. (2000). "The Broad-Spectrum Tospovirus Resistance Gene Sw-5 of Tomato Is a Homolog of the Root-Knot Nematode Resistance Gene Mi." Molecular Plant-Microbe Interactions 13(10): 1130-1138.

Butler, L. (1952). "The linkage map of the tomato." Journal of Heredity 43: 25-36.

Caicedo, A. L. (2008). "Geographic diversity cline of R gene homologs in wild populations of Solanum pimpinellifolium (Solanaceae)." American Journal of Botany 95(3): 393-398. 
Caicedo, A. L. and B. A. Schaal (2004). "Population structure and phylogeography of Solanum pimpinellifolium inferred from a nuclear gene." Molecular Ecology 13(7): 1871-1882.

Canady, M. A., V. Meglic, et al. (2005). "A library of Solanum lycopersicoides introgression lines in cultivated tomato." Genome 48(4): 685-697.

Casals, J., L. Pascual, et al. (2011). "The risks of success in quality vegetable markets: Possible genetic erosion in Marmande tomatoes (Solanum lycopersicum L.) and consumer dissatisfaction." Scientia Horticulturae 130(1): 78-84.

Causse, M. Duffe, P. et al (2004). "A genetic map of candidate genes and QTLs involved in tomato fruit size and composition." Journal of Experimental Botany 55(403): 16711685.

Causse, M., C. Friguet, et al. (2010). "Consumer Preferences for Fresh Tomato at the European Scale: A Common Segmentation on Taste and Firmness." Journal of Food Science 75(9): S531-S541.

Causse, M., V. Saliba-Colombani, et al. (2002). "QTL analysis of fruit quality in fresh market tomato: a few chromosome regions control the variation of sensory and instrumental traits." Journal of Experimental Botany 53(377): 2089-2098.

Chen, K. Y., B. Cong, et al. (2007). "Changes in Regulation of a Transcription Factor Lead to Autogamy in Cultivated Tomatoes." Science 318(5850): 643-645.

Chunwongse, J. C., L. Black, et al. (2002). Molecular mapping of the Ph-3 gene for late blight resistance in tomato. Journal of Horticultural science and Technology 77(3): 281-286.

Comai, L. and S. Henikoff (2006). "TILLING: practical single-nucleotide mutation discovery." The Plant Journal 45(4): 684-694.

Cong, B., L. S. Barrero, et al. (2008). "Regulatory change in YABBY-like transcription factor led to evolution of extreme fruit size during tomato domestication." Nature Genetics 40(6): 800-804.

Darwin, C. (1859). On the Origin of Species by Means of Natural Selection. London, J. Murray.

Darwin, C. and A. Wallace (1858). "On the Tendency of Species to form Varieties; and on the Perpetuation of Varieties and Species by natural means of selection." Journal of the Proceedings of the Linnean Society of London. Zoology 3(9): 45-62.

Darwin, S. C., S. Knapp, et al. (2003). "Taxonomy of tomatoes in the Galpagos Islands: native and introduced species of Solanum section Lycopersicon (Solanaceae) " Systematics and Biodiversity 1(1): 29-53.

Davey, J. W., P. A. Hohenlohe, et al. (2011). "Genome-wide genetic marker discovery and genotyping using next-generation sequencing." Nature Reviews Genetics 12(7): 499510.

de Candolle, A. P. (1882). L'origine des plantes cultivées. Paris.

de Vos, R. C. H., R. D. Hall, et al. (2011). Metabolomics of a Model Fruit: Tomato. Annual Plant Reviews 109-155.

Diez M.-.J. and Nuez, F. (2008). Tomato. Vegetables II Fabaceae, Liliaceae, Solanaceae, and Umbelliferae. Prohens J. and Nuez, F.: 249-323.

Dixon, M. S., D. A. Jones, et al. (1996). "The Tomato Cf-2 Disease Resistance Locus Comprises Two Functional Genes Encoding Leucine-Rich Repeat Proteins." Cell 84(3): 451-459. 
Do, P. T., M. Prudent, et al. (2010). "The influence of fruit load on the tomato pericarp metabolome in a Solanum chmielewskii introgression line population." Plant Physiology 154(3): 1128-1142.

Doebley, J. F., B. S. Gaut, et al. (2006). "The molecular genetics of crop domestication." Cell 127(7): 1309-1321.

Doganlar, S., A. Frary, et al. (2002). "Mapping quantitative trait loci in inbred backcross lines of Lycopersicon pimpinellifolium (LA1589)." Genome 45(6): 1189-1202.

Elshire, R. J., J. C. Glaubitz, et al. (2011). "A robust, simple genotyping-by-sequencing (GBS) Approach for High Diversity Species." PLoS ONE 6(5): e19379.

Ernst, K., A. Kumar, et al. (2002). "The broad-spectrum potato cyst nematode resistance gene (Hero) from tomato is the only member of a large gene family of NBS-LRR genes with an unusual amino acid repeat in the LRR region." The Plant Journal 31(2): 127136.

Eshed, Y. and D. Zamir (1995). "An Introgression Line Population of Lycopersicon pennellii in the Cultivated Tomato Enables the Identification and Fine Mapping of YieldAssociated QTL." Genetics 141(3): 1147-1162.

FAO (2010). Plant genetic ressource for food and agriculture. Rome, Food and Agriculture Organisation of the United Nations

Fernie, A. and H. Klee (2011). "The use of natural genetic diversity in the understanding of metabolic organization and regulation." Frontiers in Plant Science 2.

Fernie, A. R. and N. Schauer (2009). "Metabolomics-assisted breeding: a viable option for crop improvement?" Trends in Genetics 25(1): 39-48.

Finkers, R., H. de Weerd, et al. (january 2011). BreeDB: A database suppporting quantitative aspects of plant breeding. Plant and Animal Genomes XIX, San Diego.

Finkers, R., A. van Heusden, et al. (2007). "The construction of a Solanum habrochaites LYC4 introgression line population and the identification of QTLs for resistance to Botrytis cinerea." Theoretical and Applied Genetics 114(6): 1071-1080.

Food, Royal Norvegian Ministry of Agriculture (2008) "Svalbard global seedvault - more about the constuction from the directorate of public construction and property." 27.

Foolad, M. R. (2007). "Genome Mapping and Molecular Breeding of Tomato." International Journal of Plant Genomics 2007: 1-52.

Frary, A., Nesbitt et al (2000). "fw2.2: A quantitative trait locus key to the evolution of tomato fruit size." Science 289(5476): 85-88.

Fridman, E., F. Carrari, et al. (2004). "Zooming on a quantitative trait for tomato yield using interspecific introgressions." Science 305(5691): 1786-1789.

Gady, A., F. Hermans, et al. (2009). "Implementation of two high through-put techniques in a novel application: detecting point mutations in large EMS mutated plant populations." Plant Methods 5(1): 13.

García-Martínez, S., L. Andreani, et al. (2006). "Evaluation of amplified fragment length polymorphism and simple sequence repeats for tomato germplasm fingerprinting: utility for grouping closely related traditional cultivars." Genome 49(6): 648-656.

Grandillo, S., R. Chetelat, et al. (2011). Solanum sect. Lycopersicon Wild Crop Relatives: Genomic and Breeding Resources. C. Kole, Springer Berlin Heidelberg: 129-215. 
Grandillo, S., H. M. Ku, et al. (1999). "Identifying the loci responsible for natural variation in fruit size and shape in tomato." Theoretical and Applied Genetics 99(6): 978-987.

Gur, A., S. Osorio, et al. (2010). "hi2-1, A QTL which improves harvest index, earliness and alters metabolite accumulation of processing tomatoes." Theoretical and Applied Genetics 121(8): 1587-1599.

Gur, A., Y. Semel, et al. (2011). "Yield quantitative trait loci from wild tomato are predominately expressed by the shoot." Theoretical and Applied Genetics 122(2): 405420.

Hamblin, M. T., E. S. Buckler, et al. (2011). "Population genetics of genomics-based crop improvement methods." Trends in Genetics 27(3): 98-106.

Harlan, J. R. (1971). "Agricultural Origins: Centers and Noncenters." Science 174(4008): 468474.

He, C., V. Poysa, et al. (2003). "Development and characterization of simple sequence repeat (SSR) markers and their use in determining relationships among Lycopersicon esculentum cultivars." Theoretical and Applied Genetics 106(2): 363-373.

Hemming, M. N., S. Basuki, et al. (2004). "Fine mapping of the tomato gene for fusarium wilt resistance and elimination of a co-segregating resistance gene analogue as a candidate for I-3." Theoretical and Applied Genetics 109(2): 409-418.

Hey, J. and R. Nielsen (2004). "Multilocus methods for estimating population sizes, migration rates and divergence time, with applications to the divergence of Drosophila pseudoobscura and D. persimilis." Genetics 167(2): 747-760.

Horkheimer, H. (1973). Alimentación y obtención de alimentos en el Perú prehispánico. Lima.

Isaacson, T., G. Ronen, et al. (2002). "Cloning of tangerine from tomato reveals a carotenoid isomerase essential for the production of $\beta$-carotene and xanthophylls in plants." The Plant Cell Online 14(2): 333-342.

Itkin, M., H. Seybold, et al. (2009). "TOMATO AGAMOUS-LIKE 1 is a component of the fruit ripening regulatory network." The Plant Journal 60(6): 1081-1095.

Jarvis, D. I., A. H. D. Brown, et al. (2008). "From the Cover: A global perspective of the richness and evenness of traditional crop-variety diversity maintained by farming communities." Proceedings of the National Academy of Sciences 105(14): 5326-5331.

Jenkins, J. (1948). "The origin of the cultivated tomato." Economic Botany 2(4): 379-392.

Jimenez-Gomez, J. and J. Maloof (2009). "Sequence diversity in three tomato species: SNPs, markers, and molecular evolution." BMC Plant Biology 9(1): 85.

Kamenetzky, L., R. Asís, et al. (2010). "Genomic analysis of wild tomato introgressions determining metabolism- and yield-associated traits." Plant Physiology 152(4): 17721786.

Keurentjes, J. J. B. (2009). "Genetical metabolomics: closing in on phenotypes." Current Opinion in Plant Biology 12(2): 223-230.

Kramer, M. G. and K. Redenbaugh (1994). "Commercialization of a tomato with an antisense polygalacturonase gene: The FLAVR SAVR ${ }^{\mathrm{TM}}$ tomato story." Euphytica 79(3): 293297.

Krieger, U., Z. B. Lippman, et al. (2010). "The flowering gene SINGLE FLOWER TRUSS drives heterosis for yield in tomato." Nature Genetics 42(5): 459-463. 
Ku, H. M., S. Doganlar, et al. (1999). "The genetic basis of pear-shaped tomato fruit." Theoretical and Applied Genetics 99(5): 844-850.

Kurlovich, B. S., S. I. Rep'ev, et al. (2000). "The significance of Vavilov's scientific expeditions and ideas for development and use of legume genetic resources." Plant Genetic Resources 124: 23-32.

Labate, J. A. and A. Baldo (2005). "Tomato SNP Discovery by EST Mining and Resequencing." Molecular Breeding 16(4): 343-349.

Labate, J. A., S. Grandillo, et al. (2007). Tomato. Genome mapping and molecular breeding in plants. C. Kole. NY, Springer Publishing. 5: 1-125.

Labate, J. A., L. D. Robertson, et al. (2009). "Multilocus sequence data reveal extensive departures from equilibrium in domesticated tomato (Solanum lycopersicum L.)." Heredity 103(3): 257-267.

Labate, J. A., S. M. Sheffer, et al. (2011). "Diversity and population structure in a geographic sample of tomato accessions." Crop Science 51(3): 1068-1079.

Lanahan, M. B., H. C. Yen, et al. (1994). "The never ripe mutation blocks ethylene perception in tomato." The Plant Cell Online 6(4): 521-530.

Lanfermeijer, F. C., J. Warmink, et al. (2005). "The products of the broken Tm-2 and the durable Tm-22 resistance genes from tomato differ in four amino acids." Journal of Experimental Botany 56(421): 2925-2933.

Langford, A. N. (1937). "The parasitism of Cladosporium fulvum cooke and the genetics of resistance to it." Canadian Journal of Research(15): 108-128.

Levin, I., N. Gilboa, et al. (2000). "Fgr , a major locus that modulates the fructose to glucose ratio in mature tomato fruits." Theoretical and Applied Genetics 100(2): 256-262.

Li, W. and R. T. Chetelat (2010). " A pollen factor linking inter- and intraspecific pollen rejection in tomato." Science 330(6012): 1827-1830.

Lieberman, M., O. Segev, et al. (2004). "The tomato homolog of the gene encoding UVdamaged DNA binding protein 1 (DDB1) underlined as the gene that causes the high pigment-1 mutant phenotype." Theoretical and Applied Genetics 108(8): 15741581.

Ling, H.-Q., P. Bauer, et al. (2002). "The tomato fer gene encoding a bHLH protein controls iron-uptake responses in roots." Proceedings of the National Academy of Sciences 99(21): 13938-13943.

Ling, H.-Q., G. Koch, et al. (1999). "Map-based cloning of chloronerva, a gene involved in iron uptake of higher plants encoding nicotianamine synthase." Proceedings of the National Academy of Sciences 96(12): 7098-7103.

Lippman, Z. and S. D. Tanksley (2001). "Dissecting the Genetic Pathway to Extreme Fruit Size in Tomato Using a Cross Between the Small-Fruited Wild Species Lycopersicon pimpinellifolium and L. esculentum var. Giant Heirloom." Genetics 158(1): 413-422.

Lippman, Z. B. and D. Zamir (2007). "Heterosis: revisiting the magic." Trends in Genetics 23(2): 60-66.

Liu, J., van Eck et al (2002). "A new class of regulatory genes underlying the cause of pearshaped tomato fruit." Proceedings of the National Academy of Sciences 99(20): 1330213306. 
Lopes, J. S. and M. A. Beaumont (2010). "ABC: A useful Bayesian tool for the analysis of population data." Infection, Genetics and Evolution 10(6): 825-832.

Luckwill, L. C. (1943). "The genus Lycopersicon: an historical, biological, and taxonomical survey of the wild and cultivated tomatoes. ." Aberdeen University Studies(120): 1-44.

Manning, K., M. Tör, et al. (2006). "A naturally occurring epigenetic mutation in a gene encoding an SBP-box transcription factor inhibits tomato fruit ripening." Nature Genetics 38(8): 948-952.

Martin, G., S. Brommonschenkel, et al. (1993). "Map-based cloning of a protein kinase gene conferring disease resistance in tomato." Science 262(5138): 1432-1436.

Mazzucato, A., R. Papa, et al. (2008). "Genetic diversity, structure and marker-trait associations in a collection of Italian tomato (Solanum lycopersicum L.) landraces." Theoretical and Applied Genetics 116(5): 657-669.

McCue, G. A. (1952). "The history of the use of the tomato: an annotated bibliography." Annals of the Missouri Botanical Garden 39(4): 289-348.

McKhann, H. I., C. Camilleri, et al. (2004). "Nested core collections maximizing genetic diversity in Arabidopsis thaliana." The Plant Journal 38(1): 193-202.

McMeekin, D. (1992). "Representations on pre-columbian spindle whorls of the floral and fruit structure of economic plants." Economic Botany 46(2): 171-180.

Menda, N., Y. Semel, et al. (2004). "In silico screening of a saturated mutation library of tomato." The Plant Journal 38(5): 861-872.

Mendel, G. (1866). Experiments in plant hybridization : original traduction from Versuche über Plflanzenhybriden by W. Bateson completed by R. Blumberg, Electronic Scholarly Publishing Project.

Miller, J. C. and S. D. Tanksley (1990). "RFLP analysis of phylogenetic relationships and genetic variation in the genus Lycopersicon." Theoretical and Applied Genetics 80(4): 437-448.

Minoia, S., A. Petrozza, et al. (2010). "A new mutant genetic resource for tomato crop improvement by TILLING technology." BMC Research Notes 3(1): 69.

Monforte, A. J. and S. D. Tanksley (2000). "Development of a set of near isogenic and backcross recombinant inbred lines containing most of the Lycopersicon hirsutum genome in a L. esculentum genetic background: A tool for gene mapping and gene discovery." Genome 43(5): 803-813.

Moreau, P., P. Thoquet, et al. (1998). "Genetic Mapping of Ph-2, a Single Locus Controlling Partial Resistance to Phytophthora infestans in Tomato." Molecular Plant-Microbe Interactions 11(4): 259-269.

Mounet, F., A. Moing, et al. (2009). " Gene and metabolite regulatory network of early developing fruit tissues highlights new candidate genes for the control of tomato fruit composition and development." Plant Physiology 149(3): 1505-1528.

Mueller, L. A., R. K. Lankhorst, et al. (2009). "A Snapshot of the emerging tomato genome sequence." Plant Gen. 2(1): 78-92.

Müller, C. H. (1940a). "A revision of the genus Lycopersicon. ." U.S.D.A. Miscellanous Publications(382): 1-28.

Müller, C. H. (1940b). "The taxonomy and distribution of the genus Lycopersicon." National Horticulture Magazine(19): 157-160. 
Muños, S., N. Ranc, et al. (2011). "Increase in tomato locule number is controlled by two SNPs located near WUSCHEL." Plant Physiology. 156(4): 2244-2254.

Myles, S., J. Peiffer, et al. (2009). " Association mapping: critical considerations shift from genotyping to experimental design.." The Plant Cell Online 21(8): 2194-2202.

Nakazato, T. and E. A. Housworth (2011). "Spatial genetics of wild tomato species reveals roles of the Andean geography on demographic history." American Journal of Botany 98(1): 88-98.

Navez, B. (2011). Tomate: Qualité et préférences Centre Technique Interprofessionnel Fruits Legumes.

Nei, M., T. Maruyama, et al. (1975). " The bottleneck effect and genetic variability in populations." Evolution 29(1): 1-10.

Nesbitt, T. C. and S. D. Tanksley (2002). "Comparative sequencing in the genus Lycopersicon: implications for the evolution of fruit size in the domestication of cultivated tomatoes." Genetics 162(1): 365-379.

Nuez, F., J. Prohens, et al. (2004). "Relationships, origin, and diversity of Galápagos tomatoes: implications for the conservation of natural populations." American Journal of Botany 91(1): 86-99.

Okabe, Y., E. Asamizu, et al. (2011). "Tomato TILLING Technology: development of a reverse genetics tool for the efficient isolation of mutants from Micro-Tom mutant libraries." Plant and Cell Physiology 52(11): 1994-2005.

Ori, N., Y. Eshed, et al. (1997). "The I2C Family from the wilt disease resistance Locus I2 belongs to the nucleotide binding, Leucine-Rich Repeat superfamily of plant resistance genes." The Plant Cell Online 9(4): 521-532.

Paran, I., I. Goldman, et al. (1995). "Recombinant inbred lines for genetic mapping in tomato." Theoretical and Applied Genetics 90(3): 542-548.

Paran, I. and E. van der Knaap (2007). "Genetic and molecular regulation of fruit and plant domestication traits in tomato and pepper." Journal of Experimental Botany 58(14): 3841-3852.

Park, Y.-J., M. West, et al. (2004). "Evaluation of AFLPs for germplasm fingerprinting and assessment of genetic diversity in cultivars tomato (Lycopersicon esculentum L.)." Genome 47(3): 510-518.

Paterson, A., S. Damon, et al. (1991). "Mendelian factors underlying quantitative traits in tomato: comparison across species, generations and environments." Genetics 127: 181-187.

Paterson, A. H., E. S. Lander, et al. (1988). "Resolution of quantitative traits into Mendelian factors by using a complete linkage map of restriction fragment length polymorphisms." Nature 335: 721-726.

Peralta, I. E. and D. Spooner (2007). History, origin and early cultivation of tomato (Solanaceae). Genetic improvement of Solanaceous crops. M. K. Razdan and A. K. Mattoo. Enfield (NH), Science Publisher. 2: 1-24.

Peralta, I. E., D. Spooner, et al. (2007). "Taxonomy of wild tomatoes and their relatives (Solanum sect. Lycopersicoides, sect. Juglandifolia, sect. Lycopersicon; Solanaceae)." Systematic Botany Monographs 84. 
Peralta, I. E. and D. M. Spooner (2001). "Granule-bound starch synthase (GBSSI) gene phylogeny of wild tomatoes (Solanum L. section Lycopersicon [Mill.] Wettst. subsection Lycopersicon)." American Journal of botany 88(10): 1888-1902.

Peralta, I. E. and D. M. Spooner (2005). Morphological characterization and relationships of wild tomatoes (Solanum L. Section Lycopersicon). A Festschrift for William G. D'Arcy. T. B. Croat, V. C. Hollowell and R. C. Keating, Missouri Botanical Garden Press. 104: 227-257.

Pertuzé, R. A., Y. Ji, et al. (2002). "Comparative linkage map of the Solanum lycopersicoides and S. sitiens genomes and their differentiation from tomato." Genome 45(6): 10031012.

Piron, F., M. Nicolaï, et al. (2010). "An Induced Mutation in Tomato eIF4E Leads to Immunity to Two potyviruses." PLoS ONE 5(6): e11313.

Price, A. L., N. A. Zaitlen, et al. (2010). "New approaches to population stratification in genome-wide association studies." Nature Reviews Genetics 11(7): 459-463.

Pritchard, J. K., M. Stephens, et al. (2000). "Inference of population structure ssing multilocus genotype data." Genetics 155(2): 945-959.

Purugganan, M. D. and D. Q. Fuller (2009). "The nature of selection during plant domestication." Nature 457(7231): 843-848.

Quinet, M., J.-M. Kinet, et al. (2011). "Flowering response of the uniflora:blind:self-pruning and jointless:uniflora:self-pruning tomato (Solanum lycopersicum) triple mutants." Physiologia Plantarum 141(2): 166-176.

Ramsay, L., J. Comadran, et al. (2011). "INTERMEDIUM-C, a modifier of lateral spikelet fertility in barley, is an ortholog of the maize domestication gene TEOSINTE BRANCHED 1." Nature Genetics 43(2): 169-172.

Ranc, N. (2010). Analyse du polymorphisme de gènes de composantes de la qualité des fruits dans les ressources génétiques sauvages et cultivées de tomate ; recherche d'association gènes/QTL. Montpellier, SupAgro. Thèse de doctorat: 348.

Ranc, N., S. Muños, et al. (2008). "A clarified position for Solanum lycopersicum var. cerasiforme in the evolutionary history of tomatoes (Solanaceae)." BMC Plant Biology 8(1): 130.

Rick (1977). "Conservation of tomato species germplasm. ." California Agriculture 31((9)): 3233

Rick, C. M. (1991). "Tomato Paste: A concentrated review of genetic highlights from the beginnings to the advent of molecular." Genetics 128(1): 1-5.

Rick, C. M. and R. T. Chetelat (1995). "Utilization of related wild species for tomato improvement." Acta Horticulturae 412: 21-38.

Rick, C. M. and F. Fobes (1975). "Allozyme variation in the cultivated tomato and closely related species." Bulletin of the Torrey Botanical Club 102(6): 376-384.

Rick, C. M., J. F. Fobes, et al. (1977). "Genetic variation in Lycopersicon pimpinellifolium: Evidence of evolutionary change in mating systems." Plant Systematics and Evolution 127(2): 139-170.

Rick, C. M., J. F. Fobes, et al. (1979). "Evolution of mating systems in Lycopersicon hirsutum as deduced from genetic variation in electrophoretic and morphological characters." Plant Systematics and Evolution 132(4): 279-298. 
Rick , C. M. and M. Holle (1990). "Andean Lycopersicum esculentum var. cerasiforme: Genetic Variation and Its Evolutionary Significance." Economic Botany 44: 69-78.

Rigola, D., J. van Oeveren, et al. (2009). "High-throughput detection of induced mutations and natural variation using KeyPoint ${ }^{\mathrm{TM}}$ technology." PLoS ONE 4(3): 4761.

Robbins, M. D., S. C. Sim, et al. (2010). "Mapping and linkage disequilibrium analysis with a genome-wide collection of SNPs that detect polymorphism in cultivated tomato." Journal of Experimental Botany 62(6): 1831-1845.

Rodriguez, G. R., S. Munos, et al. (2011). "Distribution of SUN, OVATE, LC, and FAS in the tomato germplasm and the relationship to fruit shape diversity." Plant Physiology 156(1): 275-285.

Ronen, G., L. Carmel-Goren, et al. (2000). "An alternative pathway to $\beta$-carotene formation in plant chromoplasts discovered by map-based cloning of Beta and old-gold color mutations in tomato." Proceedings of the National Academy of Sciences 97(20): 1110211107.

Rousseaux, M., C. Jones, et al. (2005). "QTL analysis of fruit antioxidants in tomato using Lycopersicon pennellii introgression lines." Theoretical and Applied Genetics 111(7): 1396-1408.

Sahagún, B. d. (1988). Historia General de las Cosas de Nueva España. Madrid.

Saliba-Colombani, V., M. Causse, et al. (2001). "Genetic analysis of organoleptic quality in fresh market tomato. 1. Mapping QTLs for physical and chemical traits." Theoretical and Applied Genetics V102(2): 259-272.

Sanders, R. A. and W. Hiatt (2005). "Tomato transgene structure and silencing." Nature Biotechnology 23(3): 287-289.

Schauer, N., D. Zamir and A.R. Fernie (2004). "Metabolic profiling of leaves and fruit of wild species tomato: a survey of the Solanum lycopersicum complex." Journal of Experimental Botany 56(410): 297-307.

Schoen, D. and A. Brown (1993). "Conservation of allelic richness in wild crop relatives is aided by assessment of genetic markers." Procceedings of the National Academy of Sciences 90(22): 10623-10627.

Semel, Y., Nissenbaume et al (2006). "From the Cover: Overdominant quantitative trait loci for yield and fitness in tomato." Proceedings of the National Academy of Sciences 103(35): 12981-12986.

Shalit, A., A. Rozman, et al. (2009). "The flowering hormone florigen functions as a general systemic regulator of growth and termination." Proceedings of the National Academy of Sciences 106(20): 8392-8397.

Sharma, M., N. Singh, et al. (2008). "Expression of toxin co-regulated pilus subunit A (TCPA) of Vibrio cholerae; and its immunogenic epitopes fused to cholera toxin B subunit in transgenic tomato (Solanum lycopersicum)." Plant Cell Reports 27(2): 307318.

Sicard, A. and M. Lenhard (2011). "The selfing syndrome: a model for studying the genetic and evolutionary basis of morphological adaptation in plants." Annals of Botany 107(9): 1433-1443.

Smith, A. F. (2000). Souper tomatoes: the story of America's favorite food, Rutgers University Press. 
SolCAP (2008). USDA-CSREES awards \$5.4 million to SolCAP SolCAP News . Michigan State University, East Lansing.

Stadler, T., A. M. Florez-Rueda, et al. (2012). "Testing for "Snowballing" hybrid incompatibilities in Solanum: impact of ancestral polymorphism and divergence estimates." Molecular Biology and Evolution. 29(1): 31-34

Stevens, M. A. and C. M. Rick. (1986). Genetics and breeding. The Tomato Crop: A Scientific Basis for Improvement. J. G. A. a. J. Rudich. London, Chapman and Hall: 35-109.

Stevens, R., M. Buret, et al. (2007). "Candidate genes and quantitative trait loci affecting fruit ascorbic acid content in three tomato populations." Plant Physiology 143(4): 19431953.

Szymkowiak, E. J. and E. E. Irish (2005). "JOINTLESS suppresses sympodial identity in inflorescence meristems of tomato." Planta 223(4): 646-658.

Tadmor, Y., E. Fridman, et al. (2002). "Identification of malodorous, a wild species allele affecting tomato aroma that was selected against during domestication." Journal of Agricultural and Food Chemistry 50(7): 2005-2009.

Tam, S. M., C. Mhiri, et al. (2005). "Comparative analyses of genetic diversities within tomato and pepper collections detected by retrotransposon-based SSAP, AFLP and SSR." Theoretical and Applied Genetics 110(5): 819-831.

Tanksley, D., H. Medina-Filho, et al. (1981). "The effect of isozyme selection on metric characters in an interspecific backcross of tomato - basis of an early screening procedure." Theoretical and Applied Genetics 60(5): 291-296.

Tanksley, S. D., M. W. Ganal, et al. (1992). "High density molecular linkage maps of the tomato and potato genomes." Genetics 132(4): 1141-1160.

Tanksley, S. D., S. Grandillo, et al. (1996). "Advanced backcross QTL analysis in a cross between an elite processing line of tomato and its wild relative L. pimpinellifolium." Theoretical and Applied Genetics 92(2): 213-224.

Tanksley, S. D. and G. S. Khush (2002). Charles Madera Rick. Bibliographical Memoirs 84: 307319.

Tellier, A., I. Fischer, et al. (2011). "Fitness effects of derived deleterious mutations in four closely related wild tomato species with spatial structure." Heredity 107(3): 189199.

Tellier, A., S. J. Y. Laurent, et al. (2011). "Inference of seed bank parameters in two wild tomato species using ecological and genetic data." Proceedings of the National Academy of Sciences 108(41): 17052-17057.

Thomas, M., J. Dawson, et al. (2011). "Seed exchanges, a key to analyze crop diversity dynamics in farmer-led on-farm conservation." Genetic Resources and Crop Evolution 58(3): 321-338.

Tieman, D., M. Taylor, et al. (2006). "Tomato aromatic amino acid decarboxylases participate in synthesis of the flavor volatiles 2-phenylethanol and 2-phenylacetaldehyde." Proceedings of the National Academy of Sciences 103(21): 8287-8292.

Tikunov, Y. A. Lommen, et al. (2005). "A Novel Approach for Nontargeted Data Analysis for Metabolomics. Large-Scale Profiling of Tomato Fruit Volatiles." Plant Physiology 139(3): 1125-1137. 
van Berloo, R., A. Zhu, et al. (2008). "Diversity and linkage disequilibrium analysis within a selected set of cultivated tomatoes." Theoretical and Applied Genetics 117(1): 89-101.

van der Knaap, E., Z. B. Lippman, et al. (2002). "Extremely elongated tomato fruit controlled by four quantitative trait loci with epistatic interactions." Theoretical and Applied Genetics 104(2): 241-247.

van der Knaap, E., A. Sanyal, et al. (2004). "High-Resolution Fine Mapping and Fluorescence in Situ Hybridization Analysis of sun, a Locus Controlling Tomato Fruit Shape, Reveals a Region of the Tomato Genome Prone to DNA Rearrangements." Genetics 168(4): 2127-2140.

Van Deynze, A., K. Stoffel, et al. (2007). "Diversity in conserved genes in tomato." BMC Genomics 8(1): 465.

Villand, J., P. W. Skroch, et al. (1998). "Genetic Variation among tomato accessions from primary and secondary centers of diversity." Crop Science 38: 1339-1347.

Vrebalov, J., D. Ruezinsky, et al. (2002). "A MADS-Box gene necessary for fruit ripening at the tomato ripening-inhibitor (Rin) locus." Science 296(5566): 343-346.

Xiao, H., N. Jiang, et al. (2008). "A Retrotransposon-Mediated Gene Duplication Underlies Morphological Variation of Tomato Fruit." Science 319(5869): 1527-1530.

Yakovleff, E. a. F. L. H. (1935). "El mundo vegetal de los antiguos peruanos. ." Revista del Museo Nacional Botánica etnológica 3(3): 3-55.

Yang, W., X. Bai, et al. (2004). "Discovery of single nucleotide polymorphisms in Lycopersicon esculentum by computer aided analysis of expressed sequence tags." Molecular Breeding 14(1): 21-34.

Yeager, A. (1937). "Studies on the inheritance and development of fruit size and shape in the tomato." Journal of Agricultural Research 55: 141-152.

Yen, H. C., S. Lee, et al. (1995). "The Tomato Never-ripe Locus Regulates Ethylene-Inducible Gene Expression and Is Linked to a Homolog of the Arabidopsis ETR1 Gene." Plant Physiology 107(4): 1343-1353.

Yen, H. C., B. A. Shelton, et al. (1997). "The tomato high-pigment (hp) locus maps to chromosome 2 and influences plastome copy number and fruit quality." Theoretical and Applied Genetics 95(7): 1069-1079.

$\mathrm{Yu}$, J., G. Pressoir, et al. (2005). "A unified mixed-model method for association mapping that accounts for multiple levels of relatedness." Nature Genetics 38(2): 203-208.

Zamir, D. (2001). "Improving plant breeding with exotic genetic libraries." Nature Review Genetics 2(12): 983 - 989.

Zamir, D. (2008). "Plant breeders go back to nature." Nature Genetics 40(3): 269-270.

Zamir, D., I. Ekstein-Michelson, et al. (1994). "Mapping and introgression of a tomato yellow leaf curl virus tolerance gene, TY-1." Theoretical and Applied Genetics 88(2): 141146.

Zanor, M. I., J.-L. Rambla, et al. (2009). "Metabolic characterization of loci affecting sensory attributes in tomato allows an assessment of the influence of the levels of primary metabolites and volatile organic contents." Journal of Experimental Botany 60(7): 2139-2154. 
Zhang, X., N. A. Buehner, et al. (2006). "Tomato is a highly effective vehicle for expression and oral immunization with Norwalk virus capsid protein." Plant Biotechnology Journal 4(4): 419-432.

Zhong, X. B., J. Bodeau, et al. (1999). "FISH to meiotic pachytene chromosomes of tomato locates the root-knot nematode resistance gene $\mathrm{Mi}-1$ and the acid phosphatase gene Aps-1 near the junction of euchromatin and pericentromeric heterochromatin of chromosome arms 6S and 6L, respectively." Theoretical and Applied Genetics 98(3): 365-370.

Zuriaga, E., J. M. Blanca, et al. (2009). "Genetic and bioclimatic variation in Solanum pimpinellifolium." Genetic Resources and Crop Evolution 56: 39-51. 


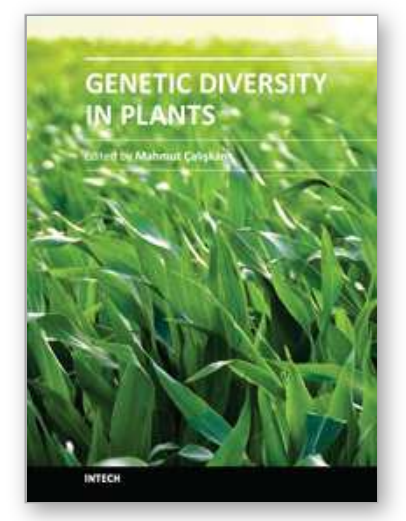

\author{
Genetic Diversity in Plants \\ Edited by Prof. Mahmut Caliskan
}

ISBN 978-953-51-0185-7

Hard cover, 498 pages

Publisher InTech

Published online 14, March, 2012

Published in print edition March, 2012

Genetic diversity is of fundamental importance in the continuity of a species as it provides the necessary adaptation to the prevailing biotic and abiotic environmental conditions, and enables change in the genetic composition to cope with changes in the environment. Genetic Diversity in Plants presents chapters revealing the magnitude of genetic variation existing in plant populations. The increasing availability of PCR-based molecular markers allows the detailed analyses and evaluation of genetic diversity in plants and also, the detection of genes influencing economically important traits. The purpose of the book is to provide a glimpse into the dynamic process of genetic variation by presenting the thoughts of scientists who are engaged in the generation of new ideas and techniques employed for the assessment of genetic diversity, often from very different perspectives. The book should prove useful to students, researchers, and experts in the area of conservation biology, genetic diversity, and molecular biology.

\title{
How to reference
}

In order to correctly reference this scholarly work, feel free to copy and paste the following:

Guillaume Bauchet and Mathilde Causse (2012). Genetic Diversity in Tomato (Solanum lycopersicum) and Its Wild Relatives, Genetic Diversity in Plants, Prof. Mahmut Caliskan (Ed.), ISBN: 978-953-51-0185-7, InTech, Available from: http://www.intechopen.com/books/genetic-diversity-in-plants/genetic-diversity-in-tomatosolanum-lycopersicum-and-its-wild-relatives

\section{INTECH}

open science | open minds

\section{InTech Europe}

University Campus STeP Ri

Slavka Krautzeka 83/A

51000 Rijeka, Croatia

Phone: +385 (51) 770447

Fax: +385 (51) 686166

www.intechopen.com

\section{InTech China}

Unit 405, Office Block, Hotel Equatorial Shanghai

No.65, Yan An Road (West), Shanghai, 200040, China

中国上海市延安西路65号上海国际贵都大饭店办公楼405单元

Phone: +86-21-62489820

Fax: $+86-21-62489821$ 
(C) 2012 The Author(s). Licensee IntechOpen. This is an open access article distributed under the terms of the Creative Commons Attribution 3.0 License, which permits unrestricted use, distribution, and reproduction in any medium, provided the original work is properly cited. 